\title{
Development of Quantitative Methods for Estimation of Aluminum Alloys Structure by Means of Image Analysis
}

\author{
Alexander A. Kazakov ${ }^{1}$, Alexander Kur ${ }^{1}$, Elena Kazakova ${ }^{1}$ \\ ${ }^{1 .}$ St.Petersburg State Polytechnical University/Metallurgical Technologies Department, St.Petersburg, \\ Russian Federation
}

Quantitative methods for evaluation of the microstructure of hypoeutectic aluminum-silicon alloys were developed and implemented as a plug-in for the Thixomet $\mathrm{PRO}^{\mathrm{TM}}$ image analyzer. $\mathrm{Al}-6 \mathrm{Si}-2 \mathrm{Cu}$ and $\mathrm{Al}-$ $10 \mathrm{Si}-2 \mathrm{Cu}-1 \mathrm{Ni}$ alloys in unmodified state and after modification were investigated. That allowed obtaining various degree of fineness of Al-Si eutectic that covered all classes of modification in accordance with the standard bar charts of the American Foundry Society (AFS).

Coefficient of eutectic fineness of these alloys was developed: at the binary image of silicon particles the average distance between all pixels located within the particles to their boundaries was calculated. The reciprocal of this average distance is called a coefficient of eutectic fineness and describes all classes of modification in accordance with the standard bar charts of AFS [Fig. 1a]. Regression equations were calculated:

$$
\begin{aligned}
& \text { UTS }(A 16 S i 2 C u)=175.56-12.28 * \mathrm{~V}_{\mathrm{i}}-2.13 * \mathrm{~V}_{\mathrm{p}}+63.81 * \mathrm{~K}_{\mathrm{d}} \\
& \text { UTS }(\mathrm{Al10Si} 2 \mathrm{CuNi})=231.54-12.28 * \mathrm{~V}_{\mathrm{i}}-2.13 * \mathrm{~V}_{\mathrm{p}}+75.33 * \mathrm{~K}_{\mathrm{d}} \\
& \text { A }_{5}(\mathrm{Al} \text {-Si2Cu })=2.993-1.102 * \mathrm{~V}_{\mathrm{i}}-0.00964 * \mathrm{~V}_{\mathrm{p}}+2.059 * \mathrm{~K}_{\mathrm{d}} \\
& \mathrm{A}_{5}(\mathrm{Al10Si} 2 \mathrm{CuNi})=0.404-0.081 * \mathrm{~V}_{\mathrm{i}}-0.00964 * \mathrm{~V}_{\mathrm{p}}+0.714 * \mathrm{~K}_{\mathrm{d}}
\end{aligned}
$$

UTS - ultimate tensile strength, $\mathrm{MPa} ; \mathrm{A}_{5}$ - relative elongation, $\% ; \mathrm{V}_{\mathrm{i}}$ - volume fraction of coarse intermetallic inclusions (greater than 5 micron); $V_{p}-$ volume fraction of pores; $\mathrm{K}_{\mathrm{d}}-$ coefficient of eutectic fineness.

They adequately describe the mechanical properties of the investigated cast alloys based on the developed coefficient of eutectic fineness and also the volume fractions of porosity and coarse (greater than $5 \mu \mathrm{m}$ ) intermetallic inclusions evaluated by using ASTM E 1245 (Fig. 1 b, c). To evaluate fineness of eutectic, the volume fraction of coarse intermetallic inclusions and porosity, panoramic images of microstructure have been obtained at a magnification of $\times 1000$ with square $0.5 \mathrm{~mm}^{2}$. Intermetallic phases have been revealed by etching in an aqueous $30 \%$ solution of caustic soda for 5-10 s. To interpret the nature of the phases which have been found by microprobe analysis, thermodynamic modeling was applied, using FactSage software powered by SGTE databases [1]. Nomograms which illustrate the effect of each of the studied parameters of the structure on the mechanical properties of $\mathrm{Al}-6 \mathrm{Si}-2 \mathrm{Cu}$ and Al-10Si-2Cu-1Ni alloys were plotted. Developed methods for forecasting hypoeutectic aluminumsilicon alloy properties by their structure can be used in their production for quality control and for acceptance tests.

Wrought aluminum alloy AA6063 has been examined in as-cast condition. Evaluation of grain structure and completeness of Fe-rich phase transformations has been carried out.

To reveal the structure, anodizing with Barker's reagent for 2 min at $25 \mathrm{~V}$ dc was employed. A special algorithm to calculate histograms of the grain size distribution and to determine average grain size has been developed for digitalizing of obtained colored images (Fig. 2a). 
Wrought aluminum alloys usually contain essential amounts of Fe-rich intermetallics located on boundaries of dendritic cells [2]. These intermetallics are characterized by different morphology determined by their temperature-time nature and crystal structure: large plate-like $\beta$-phase and compact spherical or skeletal $\alpha$-phase. $\beta$-phase deteriorates surface quality of extruded product and decreases ductile properties of the alloy [3]. To eliminate this negative effect, a homogenization process is used, which results in transformation of $\beta$-phase into $\alpha$-phase. Completeness of this process is measured by the ratio of $\alpha$-phase to $\beta$-phase. To separate Fe-containing phases, chemical selective etching by $10 \%$ water solution of $\mathrm{H}_{2} \mathrm{SO}_{4}$ heated to $70{ }^{\circ} \mathrm{C}$ has been used; this process is accompanied by coloring of $\beta$-phase particles in brown-black color, while $\alpha$-phase is outlined, which allows separation of these phases by gray level during image analysis. Another method to differentiate $\alpha$-phase from $\beta$-phase particles using elongation ratio has also been applied: elongation ratio should exceed 5 for particle to be $\beta$-phase (Fig. $2 b$ ). It has been found, that separation of Fe-containing intermetallics according to elongation ratio allowed distinguishing of Fe-rich phases more accurately in comparison with analysis based on gray level.

\section{References:}

[1] Bale C.W., Chartrand P., Degterov S.A., Calphad, 26, No. 2, (2002), p. 189.

[2] Mondolfo L.F., Structure and properties of aluminum alloys (Metallurgiya, Moscow), p. 640.

[3] Ji S., et al, Materials Science \& Engineering, 564 (2013), p. 130.
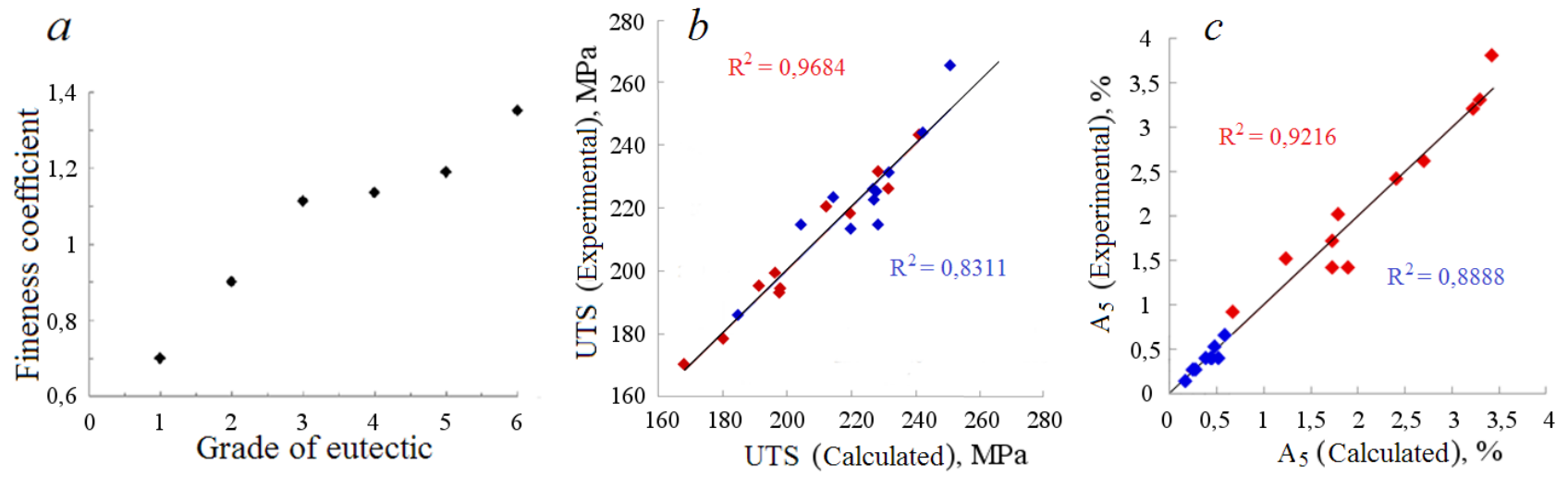

Figure 1. Evaluation of fineness coefficient according to the AFS grade of Al-Si eutectics $(a)$, correlations between calculated and experimental values for ultimate tensile strength $(b)$ and relative elongation $(c)$ of $\mathrm{Al}-6 \mathrm{Si}-2 \mathrm{Cu}(\mathrm{red})$ and $\mathrm{Al}-10 \mathrm{Si}-2 \mathrm{Cu}-1 \mathrm{Ni}$ (blue) alloys.

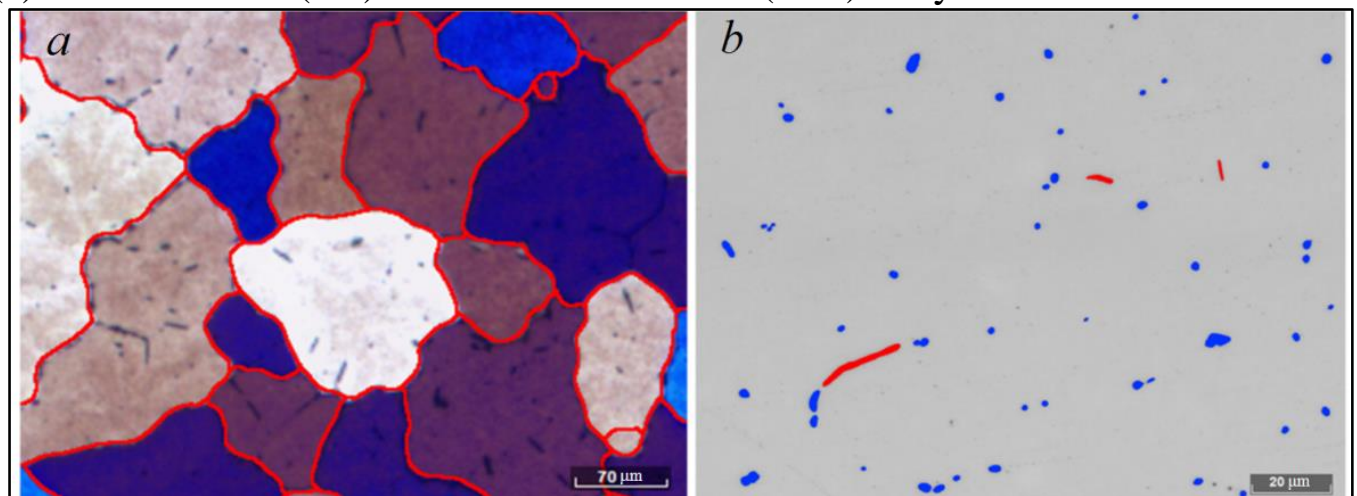

Figure 2. Recognition of grain boundaries in as-cast AA6063 alloy using new algorithm for colored images $(a)$ and elongation ratio analysis of Fe-rich intermetallics $(b)$. 